BONAFIDE: Jurnal Teologi dan Pendidikan Kristen

www.jurnal.sttissiau.ac.id/Volume 2/Nomor 2/2021/hal. 176-194.

\title{
IMPLEMENTASI MAKNA HOSPITALITAS KRISTEN TERHADAP PELAYAN GEREJA DAN ANGGOTA JEMAAT
}

\author{
Heni Maria \\ Institut Agama Kristen Negeri Toraja \\ henimaria0696@gmail.com
}

\begin{abstract}
This study aims to describe the meaning of Christian hospitality and its implementation to church servants and congregation members. The method used is qualitative with literature study and interviews with twelve informants at the Toraja Church of the Ranteba'tan Klasis Sillanan Congregation. The research results show that Christian hospitality discusses the friendship of Christians with foreigners, about how to respect our neighbors, no matter how difficult it is to respect individuals who are not the same as us, especially outsiders. Such teachings are found in the Bible. The meaning of the act of hospitality can be reflected in the stories of Bible characters, especially "Paul's hospitality." God has also handed down this hospitality through Jesus Christ to receive and redeem humans. The Bible teaching about hospitalism needs to be implemented in the lives of Christians, especially in maintaining harmonious relationships within the congregation, both relationships between congregations and the relationship between the congregation and church servants.
\end{abstract}

\section{Keywords: Christian Hospitality, Church Servant, Congregation, Harmony.}

\begin{abstract}
Abstrak. Tujuan dari penelitian ini adalah untuk menguraikan makna hospitalitas Kristen dan implementasinya kepada pelayan gereja dan anggota jemaat. Metode yang digunakan adalah kualitatif dengan studi pustaka dan wawancara kepada duabelas informan di Gereja Toraja Jemaat Ranteba'tan Klasis Sillanan. Hasil penelitian menunjukkan bahwa hospitalistas Kristen pada dasarnya membahas pertemanan umat Kristen dengan orang asing, tentang bagaimana cara menghargai sesama kita, betapapun sulitnya untuk menghargai individu yang tidak sama dengan kita, khususnya orang luar. Ajaran seperti ini terdapat dalam Alkitab. Pemaknaan akan tindakan hospitalitas dapat berkaca dari kisah tokoh-tokoh Alkitab, khususnya "hospitalitas Paulus". Hospitalitas ini juga telah diwariskan oleh Allah melalui Yesus Kristus dalam hal menerima dan menebus manusia. Ajaran Alkitab tentang hospitalis perlu diimplementasikan dalam kehidupan orang Kristen, khususnya dalam menjaga keharmonisan hubungan dalam jeemaat, baik hubungan antar jemaat maupun hubungan jemaat dengan para pelayan gereja.
\end{abstract}

Kata kunci: Hospitalitas Kristiani, Pelayan Gereja, Jemaat, Keharmonisan.

\section{PENDAHULUAN}

Dari masa ke masa seorang pelayan gereja, khususnya pendeta, selalu dituntut dapat beradaptasi dengan anggota jemaat sehingga melahirkan sebuah 
BONAFIDE: Jurnal Teologi dan Pendidikan Kristen

www.jurnal.sttissiau.ac.id/Volume 2/Nomor 2/2021/hal. 176-194.

hubungan yang harmonis antara dirinya dengan anggota jemaat. Untuk itu, dalam beradaptasi banyak hal yang perlu diperhatikan oleh pelayan gereja agar mampu mendapatkan keharmonisan yaitu keselarasan antara pelayan dan anggota jemaat. Di antaranya yang paling utama adalah haruslah bercermin dari cahaya kebenaran Firman Tuhan, menjadikan Alkitab sebagai pedoman utama sebab itulah yang menjadi identitas orang Kristen yang sesungguhnya (Saragih 2011).

Dalam keharmonisan juga tercermin sikap hospitalitas yaitu kebijakan dari keramah-tamahan dalam cinta kasih, termasuk penerimaan terhadap tamu atau orang asing. Cinta kasih terhadap sesama merupakan tindakan yang mulia dalam mewujudkan identitas Kristen yang mencerminkan akan kebenaran Firman Tuhan. Seperti yang tersurat pada Kitab Suci, bahwa mencintai orang asing merupakan tindakan untuk menjamu (band. 1Pet. 4:9)(Hershberger, 2009).

Upaya dalam menerima tamu hal ini bukanlah suatu kebiasaan yang asing bagi kehidupan kita. Kebiasaan ini merupakan sebagian besar yang kemudian dapat dijumpai dalam tradisi (budaya) dalam menerima tamu bahkan menjamu tamu. Kebudayaan tersebut tidak hanya dapat dijumpai dalam lingkup masyarakat tetapi juga dapat dijumpai dalam lingkup jemaat (Morokuhi 2017). Namun realitas yang terjadi sekarang, khususnya dalam lingkup jemaat menerima tamu (orang asing) merupakan hal yang kemudian disepelekan dan kurang mendapatkan perhatian.

Kewajiban anggota jemaat dan juga pelayan gereja adalah membangun sebuah hubungan yang baik dalam mencapai keharmonisan antara anggota jemaat dan pelayan gereja. Dalam hal ini tentu dibutuhkan sebuah interaksi antar individu 
BONAFIDE: Jurnal Teologi dan Pendidikan Kristen

www.jurnal.sttissiau.ac.id/Volume 2/Nomor 2/2021/hal. 176-194.

dan juga kelompok agar dapat membangun komunikasi supaya mencapai proses perkenalan antar individu dan juga kelompok.

Dalam lingkup jemaat, membangun hubungan yang baik bukan hanya pada saat dalam persekutuan ibadah-ibadah tetapi dalam aktivitas sehari-hari juga dapat membangun relasi yang kemudian dapat membangun keselarasan dalam saling bersambutan. Oleh sebab itulah makna dari keramahtamahan yang patut untuk diterapkan dalam memenuhi kebutuhan akan sikap saling terbuka, peduli, saling menghargai, murah hati, dan rasa untuk saling membangun. Penelitian ini ingin menggali sejauhmana jemaat memahami makna hospitalitas dalam kehidupan berjemaat? Adapun subyek penelitiannya adalah Gereja Toraja Jemaat Ranteba'tan Klasis Sillanan.

\section{METODE PENELITIAN}

Dalam penelitian ini penulis menggunakan pendekatan kualitatif deskriptif untuk membahas masalah/objek secara detail dalam kaitannya dengan kajian teologis (Suyanto 2015). Data dikumpulkan melalui studi literatur dengan memanfaatkan bermacam-macam media baik dari buku, buku harian, dan situs (Panuntun dan Paramita 2020). Selain itu, penulis juga akan menggunakan teknik wawancara kepada beberapa informan anggota jemaat dan maejelis jemat guna untuk memperoleh informasi mengenai keramahtamahan (hospitilitas). Dengan demikian penulis menggunakan survey dengan wawancara (Morrisan, Wardhani, dan Hamid U. 2012). Informan yang dilibatkan dalam penelitian ini berjumlah 12, terdiri atas anggota dan majelis jemaat. 
BONAFIDE: Jurnal Teologi dan Pendidikan Kristen

www.jurnal.sttissiau.ac.id/Volume 2/Nomor 2/2021/hal. 176-194.

\section{HASIL PENELITIAN}

\section{Pemahaman tentang Makna Hospitalitas}

Dari hasil wawancara ditemukan bahwa pemahaman informan tentang makna hospitalitas adalah sebagai berikut:

Tabel 1. Pemahaman Informan tentang Makna Hospitalitas

\begin{tabular}{|l|c|}
\hline \multicolumn{1}{|c|}{ Pemahaman tentang Hospitalitas } & $\begin{array}{c}\text { Jumlah } \\
\text { Informan }\end{array}$ \\
\hline $\begin{array}{l}\text { Keramahtamahan merupakan tindakan bercengkrama antara } \\
\text { satu sama lain }\end{array}$ & 4 \\
\hline Bertemunya banyak orang di suatu acara pesta & 2 \\
\hline Tindakan pertemuan dalam suatu rumah (perkunjungan) & 3 \\
\hline Saling menerima satu sama lain & 2 \\
\hline $\begin{array}{l}\text { Perbuatan yang dapat dilakukan di mana saja dalam bentuk } \\
\text { menerima tamu }\end{array}$ & 1 \\
\hline Jumlah & 12 \\
\hline
\end{tabular}

Dari hasil wawancara tersebut tampak bahwa umumnya informan telah paham apa yang dimaksud dengan keramahtamahan. Dengan demikian apabila pada kenyataannya terdapat kendala dalam membangun hubungan yang baik antara pelayan gereja dan anggota jemaat, maka hal tersebut tampaknya disebabkan oleh kesulitannya dalam praktek.

\section{PEMBAHASAN}

\section{Hospitalitas Kristen}

Akar kata hospitality, diartikan sebagai penerimaan, juga perjumpaan dalam penghiburan serta sebagai tindakan kerendahan hati terhadap tamu (orang asing). Dengan kata lain, hospitality adalah keramahtamahan (Selisip 2018). Secara etimologi, hospitality berasal dari kata Latin hospes yang diterjemahkan "tuan rumah" serta "orang asing". Kata lain dari hospes adalah hostis yang diartikan “musuh”(C. Lewis 2000). 
BONAFIDE: Jurnal Teologi dan Pendidikan Kristen

www.jurnal.sttissiau.ac.id/Volume 2/Nomor 2/2021/hal. 176-194.

Hospitalitas, sebuah kata yang akrab di telinga dunia mainstream, khususnya dalam usaha travel di era ini. Namun ide ini sangat dekat dan mengambil bagian penting dalam sejarah kekristenan juga, cara yang paling umum untuk mengungkap kasih sayang TUHAN Allah Israel untuk dunia ini. Dimulai dengan Perjanjian Lama, Perjanjian Baru, dengan latar belakang sejarah gereja mula-mula, ide ini digali dan dibuat sesuai pengaturan yang ada saat itu.

Hospitalitas Kristen merupakan tindakan dalam penyambutan orang asing dengan murah hati. Inilah cara orang Kristen untuk mewujudkan dan menyatakan hospitalitas yang telah dicontohkan Allah melalui Yesus Kristus dalam kitab suci. Itulah sebabnya dalam gereja hospitalitas tidak hanya merupakan strategi yang bertujuan untuk beramah-tamah bersama anggota jemaat dan sesama pelayan gereja dalam pertemuan kebaktian yang bertujuan untuk membangun keharmonisan (Lado 2020).

Menurut Diana Butler Bass dalam bukunya yang berjudul Christianity for The Rest of Us, seorang Kristen dalam menyambut tamu (orang asing), merupakan tindakan yang ada pada diri kita. Allah telah menerima kita melalui anak-Nya yaitu Yesus Kristus, dalam mewujudkan cinta kasih terhadap sesama orang Kristen (Bass 2008).

Keramahtamahan juga dapat dilihat dalam Perjanjian Lama dan Baru di mana hospitalitas merupakan akomodasi yang mengidentifikasi dengan tanggung jawab antara pengunjung dan tuan rumah. Koneksi yang memenuhi tanggung jawab itu dikomunikasikan dalam kesamaan dan mengundang, yang menggabungkan hubungan yang mengikat secara hukum. Untuk situasi ini, 
BONAFIDE: Jurnal Teologi dan Pendidikan Kristen

www.jurnal.sttissiau.ac.id/Volume 2/Nomor 2/2021/hal. 176-194.

keramahtamahan merupakan dorongan untuk membuat dan mengikuti asosiasi dalam Injil, dan lebih jauh lagi merupakan kunci dari misi dan perkembangan kongregasi prime, khususnya sebagai indikasi manusia lain (baru) (Febriana 2018).

Hospitality biasanya digambarkan karena tindakan, latihan atau keramahan yang tinggi dalam memberikan penghiburan kepada tamu. Begitu pula jika berangkat dari bahasa Yunani, keramahan digambarkan sebagai cinta terhadap orang asing yang menyenangkan. Jika berangkat dari pengertian tersebut, keramahan diartikan sebagai bentuk yang kedua antaratuan rumah atau nyonya rumah yang memberikan persembahan kepada tamu.

Melanjutkan dari ide ini, disposisi keramahtamahan tidak terbatas pada perawatan dan ruang hidup atau sekali lagi sambut orang luar ke dalam rumah. Keramahtamahan adalah disposisi mendasar terhadap orang-orang, yang dapat ditunjukkan dalam berbagai cara. Pada titik ketika tuan rumah diubah menjadi Keramahtamahan maka orang asing yang mengkhawatirkan dapat diperbaharui dengan pengunjung sejati bagi tuan rumah. Efek kontras antara tuan rumah dan pengunjung terbunuh dalam wahyu solidaritas satu sama lain.

\section{Makna Pelayan Gereja}

Pekerja di jemaat adalah orang-orang yang berdiri kokoh di pijakan dalam jemaat, khususnya pendeta, penatua dan diaken. Orang-orang yang secara teratur disinggung oleh penguasa sebagai jemaat. Sungguh Allah sendirilah yang menjadi imam dalam jemaat-Nya, dan tempat pertama dan paling tinggi di dalamnya. Meskipun demikian, Dia tidak tinggal di antara kita sehingga esensi-Nya tidak 
BONAFIDE: Jurnal Teologi dan Pendidikan Kristen

www.jurnal.sttissiau.ac.id/Volume 2/Nomor 2/2021/hal. 176-194.

dapat dilihat oleh mata kita.Akibatnya, Dia menggunakan orang untuk memilih. Seperti halnya yang telah terjadi dalam berbagai jemaat, bahwa para pekerja jemaat di berbagai kalangan adalah mereka pekerja Tuhan yang dipilih oleh Tuhan sendiri. Dalam ras politik, Tuhan melibatkan umat-Nya.Tuhan membawa kerabat-Nya untuk memanfaatkan budaya ras politik di masyarakat umum kita. Istilah yang digunakan dalam Perjanjian Baru untuk menyebut imam atau pekerja gereja adalah "diakonos". Apa yang sangat digarisbawahi dalam perjanjian baru untuk memahami sifat dan watak jabatan keagamaan dalam arti diakonos adalah mentalitas dan ketenangannya (A. Noordegraaf 2004).

Para pekerja di jemaat dipilih oleh Tuhan melalui orang-orang dari perkumpulan untuk menyelesaikan tugas-tugas luar biasa, khususnya mengajar sabda dan melakukan sakramen. Dalam hubungannya dengan hal tersebut, Luther mengungkapkan dua hal yang diidentikkan dengan pekerja gereja. Pertama-tama, umat Yesus Kristus yang hidup oleh Injil memiliki otoritas dan kekuatan, namun komitmen untuk mendelegasikan atau mengakhiri imam, pendeta serta penatualah yang kemudian tugas mereka untuk mengajar dan menjalankan dalam jemaat. Kedua, karena jemaat tidak bisa hidup tanpa ekspresi Tuhan dan juga sulit hidup tanpa pendidikan dan pengajaran, maka jemaat harus memilih orang-orang tertentu dari antara mereka untuk ditetapkan sebagai pemimpin sehingga tugas ini menunjukkan bahwa orang-orang tersebut dari jemaat memiliki kekuatan terbesar dalam kehidupan berjemaat (Lilomboba 2021).

\section{Jemaat Allah}


BONAFIDE: Jurnal Teologi dan Pendidikan Kristen

www.jurnal.sttissiau.ac.id/Volume 2/Nomor 2/2021/hal. 176-194.

Menurut KBBI, istilah "gereja" hanya merujuk pada komunitas Kristen, bukan komunitas agama lain (“Gereja” 2016). "Gereja” adalah interpretasi dari kata Yunani "ekklesia" yang berarti "dipanggil keluar." Menurut EW Bullinger, kata ini digunakan untuk merujuk pada "setiap pertemuan, terutama pertemuan individu, atau pertemuan tertentu dari mereka". Yang digunakan beberapa kali, 3 di antaranya diartikan sebagai "berkumpul" dan 112 lainnya ditafsirkan sebagai "jemaat." Mengamati dari makna kata yang diartikan sebagai "berkumpul" sangat jelas untuk memperlihatkan kepada kita bahwa kita bukanlah orang-orang percaya yang di perkumpulan sebagaimana adanya. hanyalah kata ini tidak digunakan untuk merujuk pada pertemuan orang-orang Kristen sebagaimana adanya (Christian dan Panggarra 2011).

Namun sangat jelas bahwa arti dari kata "ekklesia" dipakai juga di luar orang Kristen, juga diperuntukkan kepada mereka yang diluar orang Kristen (band.Kis. 19: 23,32,35,39 dan 41). Melihat dari makna "ekklesia" yaitu "berkumpul" juga dapat dilihat dengan penggunaan kata ini dalam Septuaginta, interpretasi Yunani kuno dari Kitab Suci Ibrani. Ditemukan bahwa kata tersebut digunakan berkali-kali. Semuanya dapat dibandingkan dengan kata Yahudi "qahal" yang berarti "kumpulan individu yang bertemu, berkelompok, sebuah aktivitas; jemaat, perkumpulan, kumpul-kumpul; dari perspektif yang lebih luas sebagai berbagai macam individu, pasukan, negara, individu yang mengerikan, individu yang adil.

\section{Hospitalitas Rasul Paulus}


BONAFIDE: Jurnal Teologi dan Pendidikan Kristen

www.jurnal.sttissiau.ac.id/Volume 2/Nomor 2/2021/hal. 176-194.

Seorang Paulus merupakan orang yang begitu membenci kepada orang Kristen. Namun ketika Paulus mengubah namanya dari nama Saulus, justru pada waktu itu ia telah berhospitalitas terhadap umat-umat percaya (orang Kristen). Awal mulanya terjadi hal ini ketika Paulus berada di Damsyik dan pada saat itulah Tuhan berhospitalitas kepada Paulus.Yang awalnya Paulus merupakan "orang asing", namun sekarang Paulus merupakan salah satu "tuan rumah" dalam tugasnya sebagai pekabar Injil. Sepanjang Paulus melakukan perjalanan Pastoralnya, ia banyak menerima respons hospitalitas dari jemaat yang telah ia kunjungi. Yang lebih menariknya lagi Paulus sangat diterima dengan baik, bahkan dalam perkunjungannya ia juga mendapatkan hospitalitas secara khusus.

Melalui suratnya bagi jemaat di Roma, ia mengabarkan Injil mengenai “tidak ada perbedaan" di antara Kristen Yahudi dengan Kristen non Yahudi. Inilah yang menjadi sikap hospitalitas Paulus yang sangat dominan yaitu tentang hubungan antara orang-orang Kristen Yahudi dan bukan Yahudi. Paulus telah memberikan gambaran hospitalitas mengenai sikap keterbukaan untuk membangun hubungan antara orang Yahudi dan bukan Yahudi serta memberikan tempat untuk saling menerima satu akan yang lain dari dua aliran tersebut, sebagaimana saudara dan keluarga dalam Kristus (Febriana 2018).

Selanjutnya berkaca dari kisah-kisah Paulus, di mana dalam Kitab Filemon 1:17, sangat jelas melalui permintaannya kepada Filemon tentang Onesimus. Paulus sangat menunjukkan kesosialannya (Hershberger 2009). Artinya bahwa Paulus telah menunjukan sikap-sikap yang perlu untuk diteladani sebagai orang Kristen untuk menerapkan tujuan dari keramahtamahan. Kisah ini juga 
BONAFIDE: Jurnal Teologi dan Pendidikan Kristen

www.jurnal.sttissiau.ac.id/Volume 2/Nomor 2/2021/hal. 176-194.

memberikan gambaran dalam menerima tamu untuk membangun hubungan yang baru terhadap orang lain. Dari hal tersebut maka tujuan dari hospitalitas Kristen dapat diaplikasikan dalam kehidupan berjemaat maupun dalam membangun relasi antar sesama.

\section{Risky Hospitality dalam Kekristenan}

Dalam kamus Bahasa Inggis (U-Dictionary) Risky diartikan sebagai "resiko" hospitality yang berarti "keramahan". Dengan demikian dapat dikatakan bahwa risky hospitality merupakan sikap yang beresiko (keramahan yang beresiko). Pada kenyataannya sikap Risky hospitality yang dulunya dikenal sebagai tindakan yang dapat memberi ancaman yang beresiko, maka praktik hospitality hanya dapat dilakukan dalam ruang lingkup yang sempit. Namun dengan meminjam pemahaman dari Duma Christian dan Dokulamo yang mengatakan bahwa praktik yang dulunya dapat beresiko, maka sekarang dapat dijinakkan dan kemudian dapat menjadi praktik dalam memperkenalkan pablik yang berbabis agama (Lakawa 2011).

Bertindak hospitalitas dalam situasi yang mencekam dan dikecualikan dalam menerima respons balik (positif atau protektif) hospitalitas di sisi lain, adalah sikap yang memanusiakan orang, atau satu sama lain, terlepas dari perbedaan identitas, dan sering digunakan sebagai komoditas politik yang memecah belah. Tidak hanya dalam ruang lingkup pendidikan tetapi gereja juga haruslah menjadi ruang yang humanis (Said 2017).

Di mana anggota jemaat, khususnya "anggota" gereja, haruslah memahami tentang pentingnya keragaman. Kenyataan yang terjadi praktik hospitalitas tidak 
BONAFIDE: Jurnal Teologi dan Pendidikan Kristen

www.jurnal.sttissiau.ac.id/Volume 2/Nomor 2/2021/hal. 176-194.

selalu mendapat ruamg dan penilaian yang positif. Karena banyak tindakan yang tidak menempatkan nilai-nilai kemanusiaan dalam keragaman, namun yang perlu diketahui bahwa keramahan bukalah hal yang tanpa risiko(Lakawa 2011).

Identitas kadang-kadang menghambat dengan penerimaan dan pertemuan dengan orang lain (pendatang) di dalam jemaat. Seharusnya Gereja menjadi wadah yang humanis, di mana para anggota jemaat terkhusus pekerja gereja harusnya dibawa pada sebuah kenyataan bahwa keberagaman adalah hakikat yang harus diterpakan dalam menerima dan saling menghargai (Imago Dei) (Tuju et al. 2021).

\section{Hospitalitas Kristen yang melahirkah Keharmonisan}

Keramahan menyiratkan demonstrasi kasih sayang terhadap orang lain (orang asing). Kemudian, pada saat itu, keramahan juga sesuatu yang tidak ada batasan untuk sikap untuk menghibur tetangga kita, tetapi juga untuk orang yang kita tidak tahu apa-apa. Kemudian, pada titik itu, keramahan adalah mentalitas terhadap berbagai hal dan keramahan adalah struktur untuk memunculkan rasa simpati dan kepedulian terhadap orang lain. Seorang Kristen harus memberikan refleksi yang layak untuk menguatkan korelasi yang nyaman bersama individu lainnya untuk koneksi yang telah dibuat (Suprabowo 2020).

Demikian juga orang Kristen harus menunjukkan adanya mentalitas keramahtamahan kekristenan. Berkaitan dengan suatu perkumpulan, sangat penting adanya simpati atau perasaan yang sungguh-sungguh tertuju kepada pekerja Jemaat, untuk keadaan ini lebih khusus kepada pendeta, apabila dalam suatu perkumpulan terdapat perhatian yang adil akan orang-orang dari majelis dan 
BONAFIDE: Jurnal Teologi dan Pendidikan Kristen

www.jurnal.sttissiau.ac.id/Volume 2/Nomor 2/2021/hal. 176-194.

imam jemaat akan membuat kesepakatan dan membuat hubungan semakin harmonis, dan jauh dari satu sama lain dari tidak adanya hal-hal yang saling mengakui.

Keramahan bergantung pada disposisi kasih sayang yang tidak terpisahkan. Persahabatan Kristen adalah hukum yang telah diberikan oleh Yesus Penguasa yang disusun dengan ungkapan "Hukum Kasih Sayang" dengan dua kualitas. Pertama-tama, cintailah Tuhan dengan segala yang ada di dalam dirimu, jiwa dan otak.

Menurut Martin dalam bukunya, seorang Kristen yang memiliki watak hospitality menyiratkan bahwa ia memperkenalkan Tuhan dalam keberadaannya dengan individu-individu di sekitarnya. Kemudian kata Hersberger, akomodasi ini juga dikomunikasikan sebagai bentuk kasih sayang bagi seluruh umat manusia dan dengan saling memahami bahwa setiap orang adalah pengunjung surgawi yang sedang bernaung, sebagaimana latar ketetanggaan yang mendasari memberikan keramahan sebagai tunggangan bagi para penjelajah. Bertetangga adalah kewajiban setiap orang dan selain ide yang harus diklaim namun harus dilatih dalam kehidupan sehari-hari secara teratur melihat seseorang.

\section{Praktik Hospitalitas Kristen}

Pada era perdana praktik hospitalitas diartikan sebagai sebuah keuntungan namun pada masa sekarang hospitalitas telah diubah menjadi sikap yang tanpa balasan. Kekristenan telah memutar balikkan landasan terpenting akan hospitalitas Yunani-Romawi karena adanya tujuan tertentu. Karena diketahui bahwa tamu 
BONAFIDE: Jurnal Teologi dan Pendidikan Kristen

www.jurnal.sttissiau.ac.id/Volume 2/Nomor 2/2021/hal. 176-194.

maupun orang asing masing-masing dapat memilih dari apa yang mereka inginkan untuk melakukan suatu tindakan, agar mereka mampu untuk menemukan manfaat dari jamuan tersebut (Morokuhi 2017).

Minimnya praktik hospitalitas yang lebih nyata dalam dunia sekuler, mengakibatkan nilai-nilai dari hospitalitas menjadi hal yang sangat memprihatinkan bagi umat percaya. Sebab itu belajar dari kisah tokoh-tokoh Alkitab yang telah menerapkan hospitalitas dalam dirinya maupun terhadap orang-orang disekitar mereka. Hospitalitas yang ditunjukkan oleh Paulus adalah situasi yang baik menghentikan eksploitasi dan untuk melawan bentuk rasisme. Maksudnya adalah melalui tindakan hospitalitas maka dapat memelihara kerukunan dan keharmonisan guna mencapai cinta kasih yang sesungguhnya.

Hal lain yang dapat dilakukan adalah memosisikan diri pada orang yang berbeda, khususnya orang asing. Oleh karena itu, dalam artian lain praktik hospitalitas ini seharusnya tidak menjauh dari setiap individu karea usaha keramahtamahan mencorakkan elemen-elemen terpenting dalam membentuk hubungan setiap individu, karena sikap hospitalitas pada kenyataannya menolak akan batasan-batasan yang kemudian mengakibatkan adanya perselisihan antar individu karena adanya suatu persaingan. Dengan adanya hospitalitas maka sikap saling menerima akan dapat terwujud tanpa melihat status sosial setiap individu.

Konsep keramahtamahan, motif utama dalam Kitab Suci yang diakui oleh semua orang Kristen, merupakan pusat dari proyek ini secara teologis. "Citra Allah sebagai tuan rumah yang baik dan ramah mencakup materi alkitabiah," tulis Christine Pohl dalam bukunya yang diterima dengan baik, Making Room: 
BONAFIDE: Jurnal Teologi dan Pendidikan Kristen

www.jurnal.sttissiau.ac.id/Volume 2/Nomor 2/2021/hal. 176-194.

Recovering Hospitality as a Christian Tradition. Para penulis Perjanjian Baru menggambarkan Yesus sebagai tuan rumah yang sopan”. Dalam bukunya The Shape of Living, teolog David F. Ford menulis bahwa keramahtamahan Yesus adalah "universal". Ciri dari praktik alkitabiah adalah memberikan keramahan tanpa memperhatikan keuntungan.

Kemudian praktik yang kaya dan berlapis-lapis yang mencakup setidaknya elemen berikut: Perasaan yang tulus mengekspresikan karakter dan benak kita akan individu lain, yaitu kerendahan hati; memperlakukan orang yang dicintai dengan hormat, yang merupakan kemurahan hati; dan bersedia untuk mengakui area di mana kita membutuhkan koreksi, yaitu meminta dan menawarkan pengampunan.

\section{Hospitalitas Kristen pada masa kini}

Kenyataannya hospitalitas merupakan suatu sikap yang kemudian dapat diaplikasikan dalam keadaan sadar (disengaja). Artinya keramahtamahan adalah bagian yang terdap dalam kehidupan muri-murid Yesus. Dengan pemahaman tersebut, maka sepatutnyalah gereja menjadi wadah untuk memperluas spirit hospitalitas. Pada kenyataanya orang asing maupun tamu itu sama atau sepadan (Febriana 2018).

Dikatakan sepadan karena tidak selamanya kedua status tersebut akan terus melekat. Artinya bahwa setiap individu memiliki pergerakan masing-masing baik itu keluar maupun masuk dari keadaan tersebut, di mana individu yang statusnya sebagai tamu kemudian juga sewaktu-waktu dapat berubah menjadi orang asing. 
BONAFIDE: Jurnal Teologi dan Pendidikan Kristen

www.jurnal.sttissiau.ac.id/Volume 2/Nomor 2/2021/hal. 176-194.

Selanjutnya, dalam mencapai akan terwujudnya sikap tersebut maka dalam membangun hubungan yang harmonis, sebagai umat percaya tindakan ini haruslah dimulai dalam bentuk ibadah-ibadah dalam sebuah jemaat. Namun tidak hanya sebatas dari bentuk itu, namun untuk terus menumbuhkan sikap saling menerima dan saling menghargai melalui hospitalitas maka juga dapat diwujudkan dalam bentuk cinta kasih terhadap sesama.

\section{Implementasi Makna Hospitalitas Kristen terhadap pelayan dan jemaat}

Keramahan dalam membantu pengembangan usaha bersama dapat menjadi kegiatan yang berisi selama ini. Joas Adiprasetya berpendapat bahwa demonstrasi pemanasan kepada pihak luar mencakup suatu tempat di sekitar dua siklus bersamaan yang berlaku untuk individu itu sendiri dan juga akan individu yang berbeda. Seperti yang ditunjukkan olehnya, "Dari satu perspektif, individu menaruh perhatian pada orang lain bisa menjadi orang asing bagiku, karena aku adalah orang asing baginya. Kemudian lagi, seseorang juga dapat melangkah lebih jauh sekali lagi memahami bahwa kebetulan "orang luar" ada di dalam diri kita masing-masing (Suprabowo 2020). Demikian juga ada sudut-sudut redup bagian dalam kita, ketika semua dikatakan dan dilakukan, tidak sepenuhnya diketahui.

Dengan demikian menjadi penting bahwa pengakuan orang luar di dalam diri sendiri akan memberdayakan individu itu untuk mengenali dan mengakui orang luar dari yang diluar dirinya dan elemen lingkungannya. Ruang-ruang terbuka lain dalam keramahtamahan menjadi persyaratan bersama sangat kontras dan berkualitas-harga diri dalam pengalaman dengan orang luar bisa sampai satu 
BONAFIDE: Jurnal Teologi dan Pendidikan Kristen

www.jurnal.sttissiau.ac.id/Volume 2/Nomor 2/2021/hal. 176-194.

sama lain. Hal Ini akan mengubah cara kita melihat orang lain, bahkan terhadap diri sendiri dalam memahami kehadiran umat manusia (Hershberger 2009).

Mempertimbangkan hospitalitas yang telah dilakukan oleh Paulus, maka sebagai orang yang percaya tentunya kita juga dapat melakukan hal ini. Karena dalam situasi ini dia benar-benar membutuhkan beberapa investasi untuk memperlihatkan bagaimana seharusnya kita menyikapi akan penerimaan orang lain dengan kerendahan hati, dalam membantu jemaat-jemaat yang telah ia kunjungi, meskipun dia mungkin telah melanjutkan perjalanannya dan meninggalkan orang itu. Itu adalah jenis simpati yang harus diselesaikan oleh orang Kristen. Terlepas dari keadaan dan kondisi yang terjadi, namun pada saat yang sama dapat membantu orang lain. Dia akan menyerahkan dirinya pada masalah dan tinggal selama beberapa waktu untuk membantu jemaat-jemaat yang ada bersama-sama dengan dia. Cerita ini merupakan penggambaran, bahwa empati membuat individu ataupun kelompok tergerak untuk menerima orang lain. Itu merupakan perasaan kasih sayang yang menggerakkan dia untuk menerima orang asing dalam keadaan apapun.

Cinta kasih adalah pendirian utama dalam mengakui keramahtamahan. Tanpa simpati, tidak akan ada rasa khawatir dan kasih sayang terhadap orang lain di sekitar kita. Dari kisah Paulus, ada juga sosok tuan rumah yang rela mengakui tanpa memikirkan hadiahnya. Itulah pelaksanaan keramahtamahan yang harus dilakukan oleh orang Kristen. Menghargai dan menerima orang luar dengan kehangatan dalam kondisi apapun juga. Maka dengan hal di atas, penulis dapat menawarkan sebuah masukkan agar gereja terbuka bagi setiap orang dan disambut 
BONAFIDE: Jurnal Teologi dan Pendidikan Kristen

www.jurnal.sttissiau.ac.id/Volume 2/Nomor 2/2021/hal. 176-194.

dengan sukacita. Keramahan bisa baik jika diwujudkan dalam instruksi untuk memperhatikan masuk atau belajar dari tamu.Biarkan pengunjung juga merasakan bahwa dia bukan pengunjung tetapi memiliki kemungkinan untuk didengar dan melakukan sesuatu.

\section{KESIMPULAN}

Hospitalitas dapat di artikan sebagai keramahtamahan terhadap sesama. Hospitalitas tidak hanya untuk mengakomodasi kebutuhan orang lain, tetapi juga mencakup keberadaan untuk satu dan kehidupan gereja. Dalam sebuah pengalaman dengan kehidupan yang sangat berbeda, Kongregasi merangkum pengakuan akan Tuhan Yang Maha Esa dan pekerjaan yang sepenuhnya didistribusikan dalam bertoleransi dan belajar satu sama lain, sehingga dunia dapat mengetahui dan memahami pentingnya Alam surga yang tenang. Dengan cara ini, cara untuk mendapatkan kesenangan dari keramahan yang nyata adalah dengan menyisihkan waktu dan ruang untuk pengunjung.

Pentingnya keramahtamahan tidak hanya mengakomodasi kebutuhan orang lain, tetapi juga memasukkan realitas perseorangan dan aktivitas bersama jemaat. Pada pengalaman bersama kehidupan itu sendiri multi-macam dan jamak, gereja menyajikan pengakuan akan Tuhan. Selanjutnya, berusaha untuk saling bertukar pengakuan dan penerimaan antar sesama, dengan tujuan agar umatpercaya dapat mengetahui dan merasakan maknanya dari Tuhan yang tenang. Selanjutnya cara dalam keramahtamahan yang nyata, itu adalah sikap yang bergerak kepada realitas kepada orang lain, sebuah kapasitas untuk 
BONAFIDE: Jurnal Teologi dan Pendidikan Kristen

www.jurnal.sttissiau.ac.id/Volume 2/Nomor 2/2021/hal. 176-194.

menyampingkan diri dan menyambut orang lain masuk mengkonfirmasi akan diri

mereka dan menyambut mereka dengan ramah.

\section{DAFTAR PUSTAKA}

A. Noordegraaf. 2004. Orientasi Diakonia Gereja (Teologi dalam Perspektif Reformasi). Jakarta: BPK Gunung Mulia.

Bass, Diana Butler. 2008. Christianity for The Rest of Us. New York: HarperOne.

C. Lewis. 2000. Elementary Latin Dictionary. Oxford Univ. Press.

Christian, Firman, dan Robi Panggarra. 2011. "Makna Kata Ekklesia Berdasarkan Matius 16:18 Dan Implementasinya Dalam Kehidupan Orang Percaya Masa Kini.” Jurnal Jaffray 9 (2): 90. https://doi.org/10.25278/jj71.v9i2.97.

Febriana, Mariani. 2018. "Hospitalitas: Suatu Kebajikan Yang Terlupakan Di Tengah Maraknya Aksi Hostilitas Atas Nama Agama." SOLA GRATIA: Jurnal Teologi Biblika dan Praktika 6 (1): 57-96. https://doi.org/10.47596/solagratia.v6i1.68.

“Gereja.” 2016. KBBI Daring. 2016.

Hershberger, Michele. 2009. Hospitalitas Orang Asing: Teman atau Ancaman. Jakarta: BPK Gunung Mulia.

Lado, Addy Purnowo. 2020. "Makna Hospitalitas Kristiani : Sebuah Kajian Atas Pemaknaan Konsep Hospitalitas Kristiani Dan Penerapannya Dalam Yogyakarta International Congregation (YIC)." Universitas Kristen Duta Wacana Yogyakarta.

Lakawa, Septemmy Eucharistia. 2011. "Risky Hospitality: Mission in the Aftermath of Religious Communal Violence in Indonesia." Boston University.

Lilomboba, Novrianto. 2021. "PROFESIONALITAS PELAYAN GEREJA." Jurnal Rumea: Pendidikan dan Teologi Kristen 1 (2): 34-45.

Morokuhi, Ones. 2017. "Tradisi Hospitalitas Untuk Pendidikan Perdamaian Di Poso." Jurnal Shanan 1 (1): 22-82. https://doi.org/10.33541/shanan.v1i1.1467.

Morrisan, Andy Corry Wardhani, dan Farid Hamid U. 2012. Metode Penelitian Survei. Jakarta: Prenada Media Group.

Panuntun, Daniel Fajar, dan Eunike Paramita. 2020. "Hospitalitas Kristen Dan Tantangannya Di Tengah Pandemi Covid-19." Harmoni 19 (1): 67-84. https://doi.org/10.32488/harmoni.v19i1.426.

Said, Nur. 2017. "Pendidikan Toleransi Beragama Untuk Humanisme Islam Di Indonesia." Edukasia: Jurnal Penelitian Pendidikan Islam 12 (2): 409-34. 
BONAFIDE: Jurnal Teologi dan Pendidikan Kristen

www.jurnal.sttissiau.ac.id/Volume 2/Nomor 2/2021/hal. 176-194.

https://doi.org/10.21043/edukasia.v12i2.2445.

Saragih, Jahenos. 2011. "Keluarga Kristen yang Harmonis." Jahenos Saragih Kumpulan Tulisan dari Seorang Hamba Tuhan. 2011. https://jahenos.wordpress.com/2011/04/22/keluarga-kristen-yang-harmonis/.

Selisip. 2018. "Hospitalitas."

Suprabowo, Gunawan Yuli Agung. 2020. "Memaknai Hospitalitas di Era New Normal: Sebuah Tinjauan Teologis Lukas 10:25-37." HARVESTER: Jurnal Teologi dan Kepemimpinan Kristen 5 (1): 43-58. https://doi.org/10.52104/harvester.v5i1.29.

Suyanto, Bagong. 2015. Metode Penelitian Sosial: Berbagai Alternatif Pendekatan. Jakarta: Prenada Group Media.

Tuju, Serva, Harls Evan R. Siahaan, Melkius Ayok, dan Donna Sampaleng. 2021. "Hospitalitas Pendidikan Kristiani dalam Masyarakat Majemuk." Jurnal Teologi Berita Hidup 3 (2): 344-55. https://doi.org/10.38189/jtbh.v3i2.99. 